\title{
Physiotherapy and the South African Bantu
}

\author{
By MARGARET ELLIS, M.C.S.P.
}

\author{
Physiotherapy Department, Johannesburg Hospital.
}

\section{INTRODUCTION.}

T he treatment of the South African Bantu is of particular interest as, quite apart from the satisfaction of the work itself, an opportunity is provided of seeing and comparing differences which exist between this field of work and European physiotherapy. It is important to know where these differences lie and how they can affect one's approach to this particular group of people. This article is therefore intended as a supplement to:-Physiotherapy in Relationship to the Treatment of Non-European Patients, given by Miss Lois Dyer to the World Congress of Physiotherapy in 1953, and published in the British Physiotherapy Journal in May, 1954.

\section{ENVIRONMENTAL EFFECTS}

The urbanised Bantu, although knowing a little of the white man's civilization, has a much lower standard of living, and his lack of knowledge of food values and care in hygiene render him susceptible to disease. Untreated, he is therefore a source of danger to the health of his white neighbour. Tuberculosis, venereal disease, and malnutrition are especially common, and may form a complicated overlay to other conditions. Climatic conditions too may influence his health, although the sweat glands, temperature regulating mechanism and autonomic nervous system seem to have undergone changes which adapt him to the high and varying temperatures of Africa.* In addition, his belief in witchcraft and superstition is still strong enough to cause serious complications in treatment., Although the urbanised Bantu may profess Christianity, he is near enough his tribal background to be ridden by a subconscious fear that either his illness is a result of bewitchment, or that by consulting a white doctor he has provoked the spirits of his ancestors, with probable retarding of recovery. This affects his attitude to medical treatment of any kind including physiotherapy, which is foreign to the Bantu's conception of the treatment of disease. Thirty years ago surgery was in the same position as physiotherapy is today, and it will only be by dint of practical demonstrations and much hard pioneer work that physiotherapy will ultimately take its rightful place in NonEuropean Hospitals. Fortunately many of the semi-educated urbanised Bantu accept physiotherapy as part of the recognised treatment of discease, but the "raw Bantu" from the reserves still regards it as one of the whiteman's mad ideas.

Group exercises in the wards, a relatively recent innovation in this hospital, are in the main regarded as an amusement to while away the tedium of a long hospital day. One old man when asked about these exercises said '.It seems to amuse the white lady and I am quite willing to make her happy." Another regarded them in a religious light and thought they were an appeal to his ancestors for co-operation.

The lower standard of living, the prevalence of debilitating diseases, and the difficult psychological background, all help to make it difficult to give physiotherapy its right place in the treatment of the Bantu.

\section{ANATOMICAL AND PHYSIOLOGICAL DIFFERENCES}

Many differences in pathology have been noted in comparing the evidences of disease in the white skinned and dark skinned races. In the past these have been related to basic racial differences, but with increasing research it is being realised that most differences can be attributed to environmental causes such as malnutrition, diet, habits and customs. For instance it has been known for many years that cancer of the antrum is much more common in the Bantu, but it has only recently been discovered that the cause may be in the special snuffs they use, which have been shown to contain carcinogens. $\dagger$

There are however, certain anatomical and physiological differences which affect the physiotherapist in his or her work.

\section{GENERAL CONSIDERATIONS.}

I. The Bantu's perception of disability is much less marked than that of the European.

Numerous examples of this can be cited. An adult Bantu male attended the outpatient department complaining of an ulcer on his little finger. It was obviously a trophic ulcer due to an ulnar palsy and the patient admitted having been stabbed in the elbow region four months earlier. He had not noticed that he was completely anaesthetic over the ulnar nerve distribution, and the paralysis of the interossei had been shrugged off as a minor disability.

Another patient attended hospital for a hydrocele, and on routine examination it was noted that he had an old dislocated shoulder, which he admitted had been caused by a fall seven years earlier.

II. This lack of perception of d.sability is probably associated with a higher pain threshold.

Although the urbanised Bantu is beginning to approach the European's attitude to pain, there is no doubt that on the whole he is more stoical to pain whose cause and origin is obvious, for example, wounds and fractures. However, when the pain is of obscure origin, such as that of pleurisy, he is liable to associate it with the presence of a snake or crab, due to witchcraft, and under these circumstances may develop a "fear complex" and be even worse than the average European in his reaction to pain.

III. After injury the Bantu rehabilitates more quickly and overcomes his disability more easily.

For example, after immobilising an elbow for four or five weeks in a collar-and-cuff sling for a supracondylar fracture, the average Bantu child recovers full function in a much shorter time with a minimum of physiotherapy. This is so obvious that many cases in the "fracture clinic" are not even sent to the physiotherapy department for treatment.

\section{SPECIFIC CONSIDERATIONS.}

\section{The Bantu's pigmented skin.}

It is a well known fact that the Transvaal, situated on a high plateau has one of the highest incidences of skin cancer for Europeans, whereas the frequency of skin cancer for the Bantu is very low. $\ddagger$ This high incidence in Europeans is almost certainly due to the action of ultra-violet rays which are much more potent in the higher altitudes whereas the pigment in the Bantu's skin acts as a filter. This protective mechanism of the Bantu's pigmented skin has its affect in the physiotherapy department. The erythema dose for U.V.R. is certainly higher, and seems to vary tremendously and is sometimes difficult to judge when the skin is very dark.

\section{Head Injuries:}

The rehabilitation of Bantu patients with cerebral injuries is a serious problem in the physiotherapy department. His

*Jokl. E. Clinical Proceedings. Vol: 3. No. 7. Sept.: 1944.

tKeen. P. et al. British êournal of Cancer. 1955. Vol.:IX Page 528.

tCohen L. et al. S.A. Medical êurnal. Vol. 26. Noy. 1952 
skull is not thicker than that of the European, as is often imagined, but the thickness of his scalp and wiryness of his hair give him a certain protection to injury. The Bantu seems also to be able to recover from cerebral injuries which would be fatal to Europeans, and the resulting disabilities, hemiplegias, paraplegias, aphasias and epileptic fits are a serious problem to the physiotherapist

III. Musculature:

The avcrage Bantu has a relatively better muscular development than the European, but there are interesting differences in the relativc power of muscle groups. 7 his is particularly noticeable in the upper limb. Whcreas the muscles of the arm and forearm are about $20 \%$ stronger than in the European, the intrinsic muscles of the hand are if anything weaker. and ccrlainly less co-ordinated for finer movements.

\section{Weight Bearing and Locomotion.}

With regard to these, there are definate anatomical and physiological differences in the lower limbs. 7 his is made clear in differences in pathology. Meniscal injuries of the knee joint are almost unknown in the Bantu races. It is a well known fact that the mining industry gives rise to many meniscal lesions, and this is madc clear in the Reef gold mines where meniscal lesions are very common in Europeans, but despite at least ten times more Bantu employees, meniscal lesions are almost unknown in Africans employed in the gold mines.

1. The following differences have been noted in the anatomy and physiology of the knee joint.

(i) The general shape of the knee joint is rounder in the Bantu, whereas the European knee joint is more oval in the transverse diameter.

(ii) The cruciate ligaments and collateral ligaments are more powerful in the Bantu.

(iii) The medial collateral ligament has a closer association with the adductor magnus tendon, a possible explanation of the relative frequency of calcification in this area of the Bantu. (Pellegrini-Streda lesion).*

(iv) Hyperextension of the knee joint is less frequent in the Bantu. This is specially noticeable in children who learn to walk with the knees in slight flexion and maintain this attitude for a much longer period.

The knee joint, a hinge joint, is not ideal for weight bearing and it would appear from the differences noted that the Bantu has maintained to a greater extent the original propulsive mechanism of the knee joint.

2. In the foot several important differences have been noted:

(i) The arches in the foot are more mobile in the Bantu and are more under muscular control. When the African puts his full weight on his foot, he appears to have a "flat foot" but as soon as the weight is released the arches spring back into position. I his is particularly noticcable in the anterior arch where increases in the transverse diameter of up to $2 \mathrm{c.m}$. have been noted during weight bearing. This is important in designing footwear for Africans and allowances should be made for these differences.

(ii) The European takes most of his weight on his heel and the heads of the first two metatarsals and the weight bearing ratio of the metatarsals is 1.2. 3. 4. 5 . In the Bantu much more weight is taken on the 5th: metatarsal and the weight bearing ratio is 1.2. 5. 4. 3. In practise this is revealed by the fact that fractures of the 5th: metatarsal cause more disability in the Bantu.

\section{COMMON CONDITIONS WHICH MAY INVOLVE} PHYSIOTHERAPY.

Traumatic.

Recent injuries keep Non-European physiotherapy departments fully occupied, and follow a certain pattern. Fractures are often multiple and heal with slow callus formation, although stiffness after long inmobilisation is amazingly slight.

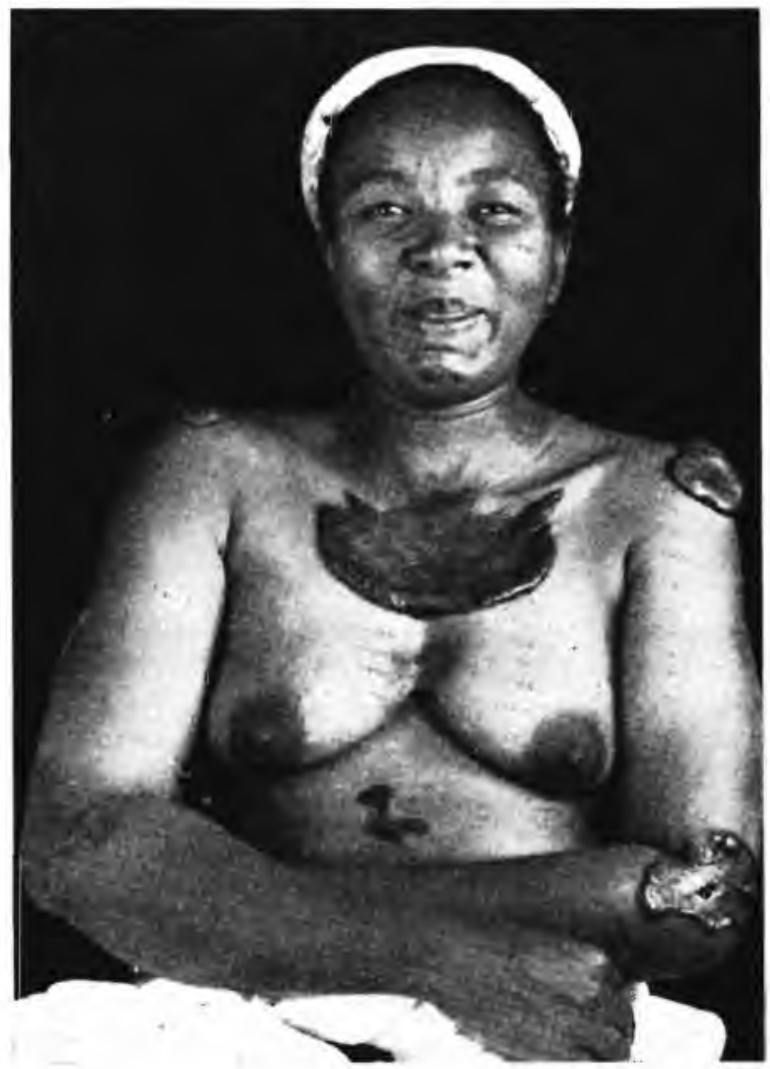

Multiple Keloids following scarification by a witch doctor.

The Bantu's inherent bellicose nature and his childlike reaction to arguments and quarrels usually result in the use of the knobkerry or the knife to finalise the dispute, and extensive fractures and severe stab wounds are very common. Severe brain damage causing hemiplegias, meningitis and brain abscesses is common, and peripheral nerve injuries are secn frequently. These cause much difficulty in the physiotherapy department on account of the long period of treatment required. Stab wounds in the chest and abdominal cavity often complicated by diaphragmatic lesions with subsequent alterations in abdominal and thoracic pressures, are very common. Many of these cases arrive late for treatment, and despite modern surgical procedures scar hernias are relatively common.

Extensive burns, a result of primitive cooking utensils and lack of knowledge about imflammable materials, are very common. The greater tendency to keloid formation. well known in the Bantu, often complicates healing and causes subseguent contractures. The treatment of these cases is complicated and in most cases plastic surgery, skin grafting, $x$-ray therapy and prolonged physiotherapy are necessary to make the patient fit again.

Orthopoedic.

The frequency of severe congenital deformities is much greater among Africans, and a high proportion of these, untreated at birth, arrive in hospital too late for physiotherapy to have much effect. Gross surgery is often necessary

* Keen P. Clinical Proccedings. Vol. 3. No. 7. Sept. 1944 


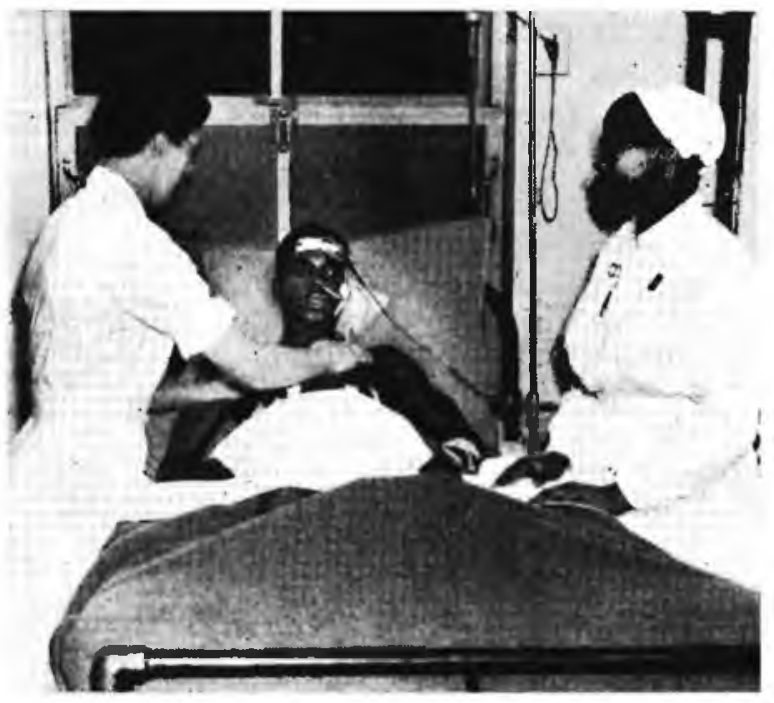

Stab wound in abdomen with herniation of intestine. Breathing exercises given within 24 hours of operation.

before any form of rehabilitation can take place. However much is being done to help the sick African by means of cripple care homes and orthopaedic clinics.

Osteomyelitis and bone joint tuberculosis, plus conditions following congenital syphilis are very common, as are tumours of bone and cartilage. Deformities following leprosy can be helped by surgery.

Inflammatory.

The high proportion of venereal disease leads to a number of inflammatory conditions which may come under the range of physiotherapy. (hief among pelvic conditions is chronic salpingitis which responds to shortwave diathermy. Septic conditions of all kinds are very common, mainly due to the fact that the average patient waits for complication to arise before attending hospital.

Gastritis, cholecystitis, and peptic ulcer are relatively rare, possibly due to easy going and unhibited temperament of the Bantu. Appendicitis, almost unknown in the Bantu thirty years ago, is becoming more and more frequent in the urbanised educated Bantu, suggesting that appendicitis is possibly one of the results of civilisation.

\section{Circulatory.}

The Bantu rarely suffers from coronary disease and one of the theories put forward, though by no means proved, is the presence of an extra coronary vessel. In addition, his simple diet, with its high starch-low fat properties, containing Jess cholesterol than that of the European may reduce the possibility of arteriosclerosis. Hypertension, though more common, does not seem to produce the symptomatic effects seen in Europeans. Heart diseases such as mitrol stenosis and endocarditis are less common but may follow rheumatic fever which however runs a milder course in Africa than in European countries. The high incidence of syphilis, congenital or otherwise, does affect the heart and blood vessels. Varicose veins with resulting leg ulcers are occasionally met. Nervous System.

Disseminated sclerosis, tabes dorsalis, and subacute combined degeneration are hardly ever encountered in the Bantu. Poliomye.itis is often met in small children but rare among adults, probably because their unhygienic living conditions give them a greater degree of immunity. When it does occur, the response of the anterior horn cells to fight the disease seems to be reduced leaving a particularly flail limb. Pneumococcal and syphilitic meningitis are fairly common as also are delirium tremens, a result of the high and somewhat haphazard alcohol intake of the Bantu, especially in urban areas where many noxious additions are made to the relatively harmless Kaffir beer.

Nervous disorders such as anxiety neurosis and functional hysteria when occuring are usually severe, and a background of witchcraft and maladjustment to a complex modern society is in these cases only too painfully evident.

\section{Chest Conditions.}

There is a high incidence of pulmonary tuberculosis, bronchiectasis, lung abcess, and empyema--pulmonary fibrosis and pleural effusions. Chest diseases run a more severe and rapid course, possibly due to low resistance and delay in attending for treatment. In largely populated urban areas, however, the most recent developments in chest surgery are available to the Bantu. For example the insertion of plastic valves in aortic deficiency has been performed on Non-Europeans. Mobile x-ray vans posted at street corners for household servants are doing much to prevent the spread of chest tuberculosis. Good food and excellent medical conditions in the "mines" combat occupational silicosis.

\section{Malignant Conditions.}

Although malignancy on the whole is probably relatively rarer in the Bantu, certain forms of cancer are more frequent. Noteable among these is primary cancer of the liver, cancer of the nasal sinuses, and cancer of the oesophagus. Malignant melanoma is more common but runs a less virulent course. Cancer of the cervix is very common.

Various Conditions.

Diabetes is rare, but becoming more frequent in urban areas. Thyrotoxicosis, another stress disease. is rare and cretinism and nyxoedema even more so.

\section{PSYCHOLOGICAL ASPECT OF TREATMENT}

It has been seen how the Bantu will "put off" coming for treatment, until incapacitation, and the failure of the witch doctors make this no longer possible.* Once inside he becomes resigned and submissive, and this attitude of relaxation under treatment, together with his high degree of patience and long-suffering renders physiotherapy easier to carry out; and this in spite of the language difficulties and the different type of mentality of the African patients. So much so, that many physiotherapists who have worked for any length of time among Non-Europeans, are often reluctant to go back to European work. Many people believe that the Bantu is more stoical with regard to pain, but this is not entirely true and, as explained earlier, a clear distinction must be made between the pain experienced with ordinary trauma due to wounds, fractures, etc., and the internal "invisible" pain such as occurs in pleurisy, renal colic, etc. For the latter type of pain the Bantu has a lowered pain threshold and if after operation he decides that his treatment is not worth the pain involved, he "gives up the ghost" completely, after which physiotherapy is well nigh impossible. Fortunately, such cases are in the minority. An average patient, following for example a lung operation, responds well in the first few days, relaxing fully with a tube in the side of his chest, coughing and breathing to order, and literally being "pushed along" at a stage when his European neighbour is still being calmed down after the operation. Then, when he should really turn the corner, his progression slackens off, his submissive fatalistic attitude devitalises him; extra vigorous exercises are necessary to produce some sort of body action, and the end result takes longer aqd is not as good as in the European.

Group work is more successful than individual if there is a good leader. The African loves to imitate and learns better this way, a factor which compensates for the language difficulties, and is made use of in instructing him in various types of work. His sense of rhythm is high, and exercises done to music are especially successful.

-Allen J. C. and Keen P. S.A. Medical Journal. Vol. 28. Dec .1954. 
As an outpatient he does not always attend regularly or come for treatment on time. If, on the other hand, in his own interests he is taken off treatment for a while, he may feel ".let down" in spite of careful explanations. Follow up work is especially difficult, as he may suddenly decide he is cured-and discharge himself. In the field of rehabilitation much is yet to be done. The African enjoys playing games, but I have not yet noticed any particular aptitude. In the wearing of appliances, and in learning to walk on crutches his progress is rapid; but crutch palsies must be carefully guarded against, owing to his weak wrists and lessend perception of disability.

\section{MATERNITY WORK.}

Ante-natal classes would not seem to be as necessary as in the European who is much more ridden by fear of pregnancy and delivery. Post-natal exercises are given, but owing to the vast numbers of African women having babies, most of the cases actually admitted to hospital are known abnormalities. The increased spinal lordosis of the Bantu female, producing a difference in the tilt, and subsequent shape of the pelvis, can cause abnormal and difficult deliveries. Ectopic pregnancies occur frequently, a result and cause of much salpingitis.

\section{TREATMENT OF CHILDREN.}

Once over their preliminary nervousness, children are usually very co-operative and enjoy their treatment, especially if it is given with other children, as, like adults, they respond well to group organisation and are excellent mimics. A serious problem however, is that of making patients understand the importance of home exercises. The language difficulties too can be so hampering that it is a great help to the physiotherapist if she can learn a few words of their language. The resulting contact gained with the child and response achieved is well worth the effort involved.

\section{CONCLUSION.}

My own experience of Non-European hospitals is that they are very happy places in which to work. Staffed by Europeans who have gone there because they really like treating the Bantu, and by Africans working among their own people, an atmosphere of harmony and goodwill is created which is very inducive to recovery of health. The small number of really chronic cases encountered, and the absence of the type of psychological overlay experienced in so much European work, makes Non-European physiotherapy, in spite of all its difficulties, creative and-highly satisfying.

A working together of all departments means that the patient is seen as a whole person, and not just as a physiotherapy case. In addition, he gets the best treatment possible, because other departments are interested in his progress in order to further their own side of the treatment. Finally the gratitude of the patient himself brings its own reward.

This article is the result of observations at the Johannesburg Non-European Hospital.

\section{ACKNOWLEDGEMENTS.}

I should like to acknowledge my gratitude to the following persons without whose help this article would not have been possible.

Dr. K. F. MILLS, The Medical Superintendant, Johannesburg Hospital, for permission to publish the article.

Dr. P. KEEN, The Medical Administrative Officer, the Non-European Hospital, Johannesburg, for assistance given in the construction of the article, and in the choosing of photographs.

Miss LOIS D YER, Physiotherapist, Roan Antelope Copper Mine Hospital, Luanshya, N. Rhodesia, for reading and amending the final draft.

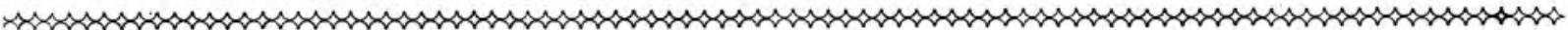

\section{CHRISTMAS CARDS RECEIVED, 1957.}

Nat. Ass. of Phys., Israel.

Danske Pysioterpeuter.

Northern Transvaal Branch S.A.S.P.

Heilgymnastiek Massage \& Physiotechniek Ned. Genootskap

F.N.B.K. Brussels.

Protea Holdings. Mr. E. Brookes.

Miss Margory Catt.

Dr. A. L. Lomey.

Kuinnliga Leg. Sjukgymnasters Riksförbund.

Australian Physiotherapy Assn. Federal Council.

Australian Physiotherapy Association.

New Zealand Society of Physiotherapists.

Miss B. H. Setzer.

United Cerebral Palsy Ass. of S.A. Executive and Staff.

Zentralverbandes Krankengymnastik. e.V.

Mr. A. Rothberg.

Miss M. J. Neilson, Secretary C.S.P.

Miss G. M. Griffin. President W.C.P.T.

National Council for Care of Cripples.

Norske Sykegymnasters Landsforbund.

Miss Joyce Crosby.

"Colonial Mutual."

Western Province Branch S.A.S.P.

American Physical Therapy Association.

"Avalon."

\section{JOURNALS RECEIVED}

"Physiotherapy." Chartered Soçiety of Physiotherapy.

S.A. Medical Journal.

Medical Proceedings. S.A. Journal for advancement of Medical Science.

Rehabilitation in S.A. Published by Dept. of Labour for S.A. Rehabilitation Council.

The Physiotherapy Review.r American Physical Therapy Association. June-November, 1957.

Heilgymnastiek Massage en Physiotechniek. Nederlandsch Tydschrift.

Sjukgymnasten. Kvinnliga Legitimerade Sjukgymnasters Riksförbund.

Sykegymnaster. Norske Sykegymnasters Landsferbund.

Finlands Medekalgymnast.

Tidskrift for Danske Fysioterapeuter.

Revue des Kinesitherapeutes. Organe de la Fédération des Masseurs-Kinesitherapeutes de France et de l'Union Français.

Krankingymnastik. Zentralverbandes Krankengymnastik. e.V.r

Journal of S.A. Logopoedic Society.

Members who would care to read any of the above journals may borrow them for a period of one month on application to the Editor. After three months they will be sent to the Library, Witwatersrand University. 